\title{
BIRD STRIKE AS A MECHANISM OF THE MOTION IN MIRCE MECHANICS
}

\author{
Dr Jezdimir Knežević* \\ MIRCE Akademy, Woodbury Park, Exeter, United Kingdom
}

Birds represent a serious, but often misunderstood, threat to aircraft. Most bird strikes do not result in any aircraft damage, but some bird strikes have led to serious accidents involving aircraft of every size. According to Bird strike Committee USA, bird and other wildlife strikes to aircraft result in over $\$ 600$ million in damage to U.S. civil and military aviation each year. The lives of the crew and passengers are also at risk. Since 1988, over 200 people have been killed worldwide as a result of encounters with birds and other wildlife. Thus, this paper addresses bird strike from MIRCE Mechanics point of view, which means that it is considered as a mechanism that generates a functionability event which causes the motion of a system from positive to negative functionability state. The paper provides vital information about the physical properties of most common birds that are required for predictions of their impacts on aircrafts, at the design stages as a scientific method for the evaluation of alternatives.

Key words: Birds, MIRCE Mechanics, Strikes, Functiones, Aircrafts

\section{INTRODUCTION}

Birds first took to the air about 150 million years ago. Humans first took to the air on $17^{\text {th }}$ December 1903. Consequently, when aircraft and birds are destined to use the same airspace at the same time, collisions occur. The first collision came soon, on 7 September 1905. From the Wright Brothers diaries, "Chased flock of birds for two rounds and killed one which fell on top of the upper surface and after a time fell off when swinging a sharp curve." [08] This was the first reported bird-aircraft strike. Because of the location near Dayton, Ohio, and time of year, the bird struck was probably a redwinged blackbird. The first fatally came on April 3, 1912, while making an exhibition flight over Long Beach in California, Calbraith Perry Rogers flew into a flock of birds, causing the plane to crash into the ocean. His died from broken neck and damaged thorax by the engine of the aircraft.

Since those initial bird strikes, aircraft designs and performance have changed dramatically and bird strike populations increased together with a air traffic. As a result, over 125 civil aircraft have been destroyed and over 255 civilian lives have been lost worldwide due to bird strike strikes from 1960 to 2004. [04] During this same period, bird strike strikes have resulted in at least 333 military aircraft destroyed and over 150 military personnel killed. [07]

The onset of the jet age revolutionized air travel, but magnified the bird strike problem. Early piston-powered aircraft were noisy and relatively slow. Bird strike could usually avoid these aircraft, and strikes that did occur typically resulted in little or no damage. However, modern jet aircraft are fast and relatively quiet, and their engine fan blades are often more vulnerable than propellers to bird strike damage. When turbine-powered aircraft collide with birds or other bird strike, serious structural damage and engine failure can occur.

Multiple-engine damage from the ingestion of flocks of birds is of particular concern as the fleet of two-engine passenger aircraft increases in the USA. In $1969,75 \%$ of the 2,100 passenger aircraft had 3 or 4 engines. In 1998, the fleet had grown to 5,400 primarily turbine-powered aircraft, of which only $30 \%$ had three or four engines. By 2008 , the fleet will consist of about 7,000 aircraft, and less than $10 \%$ will have three or four engines.

Air travel has become a global phenomenon. Aircraft have also assumed a vital role in tactical and logistical military operations. These factors have resulted in increased air traffic. For example, commercial air movements in the USA increased about 3\% per year between 1985 and 2004.

Environmental protection programs, world wide, have contributed to considerable increases in populations of many large-bodied species such as cormorants, cranes, geese, gulls, herons, pelicans, falcons, eagles, owls, vultures and wild turkeys. 
Almost all of these species have body masses over 4 pounds $(1.8 \mathrm{~kg})$, which exceed the airframe and engine certification standards for bird strike strikes. These concurrent increases in air traffic and bird strike populations contribute to an increased probability of damaging bird strikes. These two factors, combined with the increased speed, quietness, and vulnerability of modern aircraft, interact to form the basis of the bird strike problem that airport manager's face. As a final factor, airport managers also face increased concerns about airport liability in the aftermath of damaging bird strike strikes.

Bird strike is attracted to an airport environment because desirable food, water, or habitat is present. The majority of bird strike strikes occur within the immediate airport environment: $74 \%$ of all strikes occur at or below 500 feet above ground level (AGL). Eighteen of the 19 civil and military largetransport aircraft destroyed because of bird strikes between 1960 and 2004 resulted from strikes that occurred on the airport. Therefore, most bird strike involved in strikes is using the airport or its immediate vicinity, and the most logical place to begin correcting the problem is on and near the airport.

Consequently, using principles of MIRCE Mechanics his paper considers a bird strike as a mechanism that generate sufficient mechanical energy to cause occurrence of a negative functionability event, NFE, that causes the motion of a system from positive to negative functionability state, NFS.

\section{MIRCE MECHANICS}

MIRCE Mechanics: is a scientific theory of the motion of observable functionability phenomena through the life of maintainable systems. Its axioms, mathematical formulas, rules and methods enable accurate predictions of a system's measurable functionability performance characteristics like reliability, availability, punctuality and others to be made with probabilistic regularity. [05]

According to MIRCE Mechanics the motion of functionability through the life of maintainable systems is generated by occurrence of functionability events that cause the change in functionability state of a system. All physical phenomena that cause the motion of a system from the positive to negative functionability states are known as negative functionability events. Mechanisms that generate negative functionability events belong to the following three categories:

- Overstress mechanisms, where acting stresses generated by mechanical, electrical, thermal, radiation, chemical and other type of energy exceed that strength of components and systems subjected.

- Wearout mechanisms, where cumulative damage, generated by mechanical, electrical, thermal, radiation, chemical and other type of energy, is accumulated through the process like, corrosion, fatigue, creep, wear and similar.

- Human actions, where the transition from positive to negative state results from direct decision taken by humans. Most frequently these actions are performed as a part of scheduled maintenance tasks performed to check the state of a system, to preventively replace predetermined components or to install modified components.

Hence, to understand the mechanisms that generate negative functionability events analysis of over tens of thousands of components, modules and assemblies of systems in defence, aerospace, transportation, motorsport, nuclear, communication and other industries, had been studied at the MIRCE Akademy. It has lead to the formulation of the $1^{\text {st }}$ Axiom of MIRCE Mechanics, which states, "The probability of transition to negative functionability state at any instant of time is greater than zero" [05]. As it has a profound impact on all aspects of the in-service life on any maintainable system several research studies have been performed by the Master and Doctoral students of the MIRCE Akademy with aim to understand the physical mechanisms that caused their occurrences.

Using the same method and principles of MIRCE Mechanics as Zaczyk [10] this paper addresses bird strike from Mirce Mechanics point of view. It means that a bird strike is considered an overstress mechanism that generate sufficient mechanical energy to generate a negative functionability event, NFE, that causes the motion of a system from positive to negative functionability state, NFS.

\section{SELECTED EXAMPLES OF BIRD STRIKES IN AVIATION INDUSTRY SINCE 1960}

The U.S. Department of Agriculture, through an interagency agreement with the Federal Aviation Administration, compiles a database of all reported bird/wildlife strikes to U.S. civil aircraft and to foreign carriers experiencing strikes in the USA. Over 87,000 strike reports from over 1,650 airports have been compiled, 1990-2008 [04].

The FAA estimates that this represents only about $20 \%$ of the strikes that have occurred. The following historical examples of strikes from 
1905-1989 and examples from the database from 1990-2008 are presented to show the serious impact that strikes by birds or other wildlife can have on aircraft. These examples demonstrate the widespread and diverse nature of the problem and are not intended to criticize individual airports. Many of the strike examples reported here occurred off airport property during descent, approach or climb.

Selected examples of the bird strikes from [04] are presented below:

- A Lockheed Electra turbo-prop ingested European starlings into all four engines during takeoff from Boston Logan Airport (Massachusetts). The plane crashed into Boston Harbor, killing 62 people, on $4^{\text {th }}$ October 1960. Following this accident, the FAA initiated action to develop minimum bird ingestion standards for turbine-powered engines.

- On 26th February 1973 at the departure from Atlanta's Peachtree-Dekalb Airport (Georgia), a Lear 24 jet struck a flock of brownheaded cowbirds attracted to a nearby trash disposal area. Engine failure resulted. The aircraft crashed, killing seven people and seriously injuring one person on the ground. This incident prompted the FAA to develop guidelines for the location of solid waste disposal facilities on or near airports.

- On departure roll from John F. Kennedy International Airport (New York), the pilot of a DC-10 aborted takeoff after ingesting gulls into one engine, on 12 November 1975. The plane ran off runway and caught fire as a result of engine fire and overheated brakes. The resultant fire destroyed the aircraft. All 138 people on board were evacuated safely.

- A Convair 580 departing Kalamazoo Airport (Michigan) ingested one American kestrel into an engine on take-off, on 25 July 1978. The aircraft crashed in a nearby field, injuring 3 of the 43 passengers.

- In 1980; Royal Air Force Nimrod aircraft lost control and crashed after ingesting a number of birds into multiple engines at Kinloss Scotland.

- The pilot of a Bellanca 1730, during the landing process at Clifford, Texas, saw two "buzzards" on final approach. Hence, he added power and maneuvered to avoid them, then continued approach, which resulted in a landing beyond the intended point. As the middle of the runway was higher than either end, the pilot was unable to see a large canine moving to- ward the landing area until aircraft was halfway down the runway. A go-around was initiated, but the lowered landing gear hit some treetops causing the pilot to loose control. The aircraft came to rest about 250 yards from initial tree impact after flying through additional trees. The aircraft suffered substantial damage, and two people in the aircraft were seriously injured. The event took plate on 18 June 1983.

- In September 1987; U.S. Air Force B1-B lost control and crashed after an American white pelican struck the wing root area and damage a hydraulic system. The aircraft was on a low level, high speed training mission in Colorado, USA. Only three of the six occupants have survived this negative functionability event.

- On the 5th November 1990, during takeoff at Michiana Regional Airport (Indiana), a BA-31 flew through a flock of mourning doves. Several birds were ingested in both engines, and take-off was aborted. Both engines were destroyed. Cost of repairs was $\$ 1$ million, and time in NFS was 60 hours.

- A Citation 550, taking off from Angelina County Airport (Texas), on $30^{\text {th }}$ December 1991, struck a turkey vulture. The strike caused major damage to the engine number 1 and resulting shrapnel caused minor damage to the wing and fuselage. Cost of repairs was $\$ 550,000$ and time in NFS was 2 weeks.

- On the $3^{\text {rd }}$ December 1993, a Cessna 550 struck a flock of geese during the initial climb out of DuPage County Airport (Illinois). The pilot heard a loud bang, and the aircraft yawed to the left and right. Instruments showed loss of power to engine number 2 and a substantial fuel leak on the left side. An emergency was declared, and the aircraft landed at Midway Airport. The cost to repair two engines was $\$ 800,000$, and time the aircraft spent 3 months in NFS.

- An Air France Concorde, at about 10 feet AGL while landing at John F. Kennedy International Airport (New York), ingested one or two Canada geese into engine number 3 , on the $3^{\text {rd }}$ June 1995. The engine suffered an uncontained failure and its shrapnel destroyed the engine number 4 and cut several hydraulic lines and control cables. The pilot landed safely, but the runway was closed for several hours. The repair cost was around $\$ 7$ million.

- Airborne Warning and Control System aircraft (known as AWACS) crashed on $22^{\text {nd }}$ 
September 1995 killing all 24 on board. The cause of accident was ingestion of four Canada geese into engines 1 and 2 during takeoff from Elmendorf Air Force Base (Alaska).

- NATO E-3 AWACS aircraft struck a flock of birds during takeoff at Aktion airport in Greece, on 14 July 1996 . The crew aborted the takeoff and the aircraft overran the runway. The aircraft was not repaired, but none of the crew was seriously injured.

- On the $15^{\text {th }}$ July 1996; Belgian Air Force Lockheed C-130; struck a large flock of starlings during approach to Eindhoven, Netherlands and crashed short of the runway. All four members on the crew and 30 of the 37 passengers were killed.

- A Boeing-727 departing Washington DC Reagan National Airport struck a flock of gulls just after takeoff, ingesting at least one bird, on 5 October 1996. One engine began to vibrate and was shut down. As the burning smell entered the cockpit, pilot declared an emergency was declared, and the aircraft, carrying 52 passengers, landed at Washington Reagan National. Several engine blades were damaged.

- On the $7^{\text {th }}$ January 1997, an MD-80 aircraft struck over 400 blackbirds just after take-off from Dallas-Fort Worth International Airport (Texas). Almost every part of the plane was hit. The pilot declared an emergency and safely landed. Substantial damage was found on various parts of the aircraft, and engine number 1 had to be replaced. The runway was closed for 1 hour. The birds had been attracted to an un-harvested wheat field close to the airport.

- While climbing through 3,000 feet, following takeoff from Houston Intercontinental Airport (Texas), on 9 January 1998, a Boeing-727 struck a flock of snow geese with three to five birds ingested into one engine. The affected engine lost all power and was destroyed. The radome was torn from aircraft and leading edges of both wings were damaged. The pitot tube for the first officer was torn off. After declaring emergency the flight returned safely to Houston with major damage to aircraft.

- On the $22^{\text {nd }}$ February 1999, a Boeing-757 departing Cincinnati/Northern Kentucky International Airport was forced to return and make an emergency landing after hitting a large flock of starlings. Both engines and one wing received extensive damage. Around 400 dead starlings were found on the runway area.
- DC-10-30, belonging to an American-owned cargo company, ingested a fruit bat into one engine at 250 feet AGL, while departing from Subic Bay, Philippines, on 7th February 2000. The aircraft returned to the airport safely. Five damaged fan blades had to be replaced keeping aircraft negative functionability state for 3 days. Total repair and related costs exceeded $\$ 3$ million.

- An MD-11 departing Portland International Airport (Oregon), on 21st January 2001 ingested a herring gull into engine number 3 during the takeoff run. The engine stall blew off the nose cowl that was sucked back into the engine and shredded. The engine had an un-contained failure. The pilot aborted take-off and safely landed 217 passengers, with two blown tires.

- On the $9^{\text {th }}$ March 2002, a Canadair RJ 200 at Dulles International Airport, Washington DC, struck two wild turkeys during the takeoff roll. One of them shattered the windshield spraying the cockpit with glass fragments and remains.

- A Boeing 767 departing Logan International Airport in Boston, encountered a flock of over 20 double-crested cormorants, on 19 October 2002. At least 1 cormorant was ingested into engine number 2 . There were immediate indications of engine surging followed by compression stall and smoke from the engine. The engine was shutdown. An overweight landing with one engine was made without incident. The nose cowl was dented and punctured. There was significant fan blade damage with abnormal engine vibration. One fan blade was found on the runway. The aircraft was towed to the ramp. Hydraulic lines were leaking, and several bolts were sheared off inside engine. Many pieces fell out when the cowling was opened. The aircraft spent 3 days in negative functionability state and the total repair bill was $\$ 1.7$ million.

- A Bombardier de Havilland Dash 8 collided with a flock of lesser scaup ducks at 1,300 feet AGL on approach to Rogue Valley International Airport (Oregon) on the 8 January 2003,. At least one bird penetrated the cabin and hit the pilot who turned control over to the first officer for landing. Emergency power switched on when the birds penetrated the radome and damaged the DC power system and instruments systems.

- On the $4^{\text {th }}$ September 2003, a Fokker 100 struck a flock of at least five Canada geese over the runway shortly after take-off at La- 
Guardia Airport (New York), ingesting one or two geese into engine number 2 . The pilot was unable to shut the engine down with the fuel cutoff lever, so the fire handle was pulled and the engine finally shut down. The flight was diverted to nearby JFK International Airport where a landing was made. A depression on the right side of nose behind radomes was found with a maximum depth of $10 \mathrm{~cm}$. Impact marks were found on the right wing. A fan blade separated from the disk and penetrated the fuselage. Several fan blades were deformed. Holes were found in the engine cowling. Bird remains were recovered and identified by Wildlife Services.

- A Boeing 757 during a takeoff run from Portland International Airport (Oregon) hit five mallards and returned with one engine out, on 17 February 2004. At least one bird was ingested, and parts of five birds were collected from the runway. As the damaged engine was beyond repair, the new one was fitted at the cost of $\$ 2.5$ million, keeping the aircraft 3 days in NFS.

- An Airbus 319 climbing out of Portland International Airport (Oregon) ingested a great blue heron into engine number 2 , causing extensive damage, on 15 April 2004. The pilot shut the engine down as a precaution and made an emergency landing. The runway was closed 38 minutes for cleaning. The engine and nose cowl were replaced at the cost of $\$ 388,000$, keeping aircraft in NFS for 72 hours.

- A great horned owl, on 14 June 2004 struck a Boeing 737during a nighttime landing roll at Greater Pittsburgh International Airport (PA). The bird severed a cable in front main gear and disabled the steering system causing the aircraft ran off the runway and became stuck in mud. Passengers were bused to the terminal. Repair team replaced 2 nose wheels, 2 main wheels and brakes keeping the aircraft negative functionability state for 24 hours at the total cost of $\$ 20,000$.

- Departing Chicago O'Hare (Illinois), on 16 September 2004, a MD 80 hit several doublecrested cormorants at 3,000 feet AGL and 4 miles from airport. Engine number 1 caught fire and failed, sending metal debris to the ground in a Chicago neighborhood. The aircraft made an emergency landing back at O'Hare with no injuries to any of the 107 passengers.

- On the $24^{\text {th }}$ October 2004. A Boeing 767 de- parting Chicago O'Hare (Illinois) hit a flock of birds during the take-off run. A compressor stall caused the engine to flame out. A fire department got calls from local residents who reported seeing flames coming from the plane. The pilot dumped approximately 11,000 gallons of fuel over Lake Michigan before returning to land.

\section{EFFECTS OF BIRD STRIKE}

The nature of aircraft damage from bird strikes, which is significant enough to create a high risk to continued safe flight, differs according to the size of aircraft.

Small, propeller-driven aircraft are most likely to experience the hazardous effects of strikes as structural damage, such as the penetration of flight deck windscreens or damage to control surfaces or the empennage.

Larger jet-engined aircraft are most likely to experience the hazardous effects of strikes as the consequences of engine ingestion. Partial or complete loss of control may be the secondary result of either small aircraft structural impact or large aircraft jet engine ingestion. Loss of flight instrument function can be caused by impact effects on the Pitot Static System air intakes which can cause dependent instrument readings to become erroneous.

Complete Engine failure or serious power loss, even on only one engine, may be critical during the take-off phase. In the case of bird ingestion into more than one engine, all aircraft are vulnerable to loss of control. Such hazardous ingestion is infrequent but may result from the penetration of a large flock of medium sized birds or an encounter with a smaller number of very large ones.

In some cases, especially with smaller fixed wing aircraft and helicopters, windscreen penetration may result in injury to pilots or other persons on board and has sometimes led to loss of control. Although relatively rare, a higher altitude bird strike to a pressurised aircraft can cause structural damage to the aircraft hull which, in turn, can lead to rapid depressurisation. A more likely cause of difficulty is impact damage to extended landing gear assemblies in flight, which can lead to sufficient malfunction of brakes or nose gear steering systems to cause directional control problems during a subsequent landing roll.

A relatively common but avoidable significant consequence of a bird strike on the take off roll is a rejected take off decision which is either made after V1 or which is followed by a delayed or incomplete response and which leads to a runway excursion off the departure end of the runway. 


\section{DETERMINATION OF IMPACT FORCE}

In classical mechanics impulse or impact refers to something that changes momentum of an object. The impulse of a force acting for a given time interval is equal to the change in linear momentum produced over that interval. It is denoted as $\mathrm{J}$ and it is quantified through the product of a force, $\mathrm{F}$, and the time, $t$, during which it acts. Impulse is a vector quantity since it is the result of integrating force, a vector quantity, over time. The SI unit of impulse is the Newton second (Ns) or, in base units, the kilogram meter per second $(\mathrm{kg} \cdot \mathrm{m} / \mathrm{s})$.

Based on the above, for the cases where the mass is constant, the impulse is defined as: where:

$J=F \Delta t=m V_{f}-m V_{i}$

$\mathrm{F}$ is the resultant force applied,

$\Delta t t$ duration of impact

$m$ is the mass of the object,

$v_{2}$ is the final velocity of the object at the end of the time interval,

$v_{1}$ is the initial velocity of the object when the time interval begins.

Under the following assumptions the equation 1 becomes equation 2 :

- Head on collision

- Bird is riding with the aircraft after the collision

- Bird's velocity is negligible compared to that of the aircraft

- Total time taken to crush the bird (estimated impact time)

- Impulsive applied to the bird

The above expression could be used for the calculation of the force generated by the collision between an aircraft. The estimated impact time, for all practical purposes, could be determined as a ratio of the length of the bird, LB, and the speed of the aircraft, $A V$, thus:

$$
\begin{aligned}
& F=\frac{m V_{f}}{\Delta t}\left[\frac{\mathrm{kgm}}{\mathrm{s}^{2}}\right] \\
& \Delta t=\frac{B L}{A V}[s]
\end{aligned}
$$

For example, the impact force will be $101338 \mathrm{~N}$ (10.3 tonnes) will be generated in the collusion between an aircraft that flies $260 \mathrm{~m} / \mathrm{s}$ and a bird whose length is 20 centimeters and weight 300 grams.

\section{BIRD STRIKE RELATED RESEARCH AT THE MIRCE AKADEMY}

During last 15 years extensive research studies were performed, by numerous students and members of staff of the MIRCE Akademy, where a large number of negative functionability phenomena were observed and analysed like inherent failures, maintenance errors, foreign object damage, as-bad-as-old repairs, not fault found, ageing processes, storage and transport related phenomena, fatigue cracks, impact of solar radiation, sand, wind, ice on system machine durability, material vacancies and many others.

\section{DIMENSIONS AND HABITATION ANALYSIS OF BIRDS}

During the summer 2013 the research was conducted to determine the physical characteristics of birds that have the most frequent and consequential impact on the aircraft safety. The objectives of the research were to collect the data regarding the physical properties of birds, like their weight and length, which is necessary information for the calculation of the impulse force to be made in accordance to the equation 2 , for various types of aircraft.

The same research was also focused on the determination of the geographical locations of their habitats, as vital information for the flying public in the related area of the world. The following two examples will be used to illustrate the importance of location and the seasonal impacts on the birds

1. It has been determined that Israel has the world's largest density of migrating birds during the migration season. Consequently, since 1972 the total number of bird strikes recorded in Israel was [3]:

- 637 with transport planes and light aircraft.

- 696 with helicopters,

- 1,282 with military aircraft,

2. From their Arctic breeding grounds in Canada and Greenland, each autumn, greater snow geese arrive to Chincoteague National Wildlife Refuge, Virginia and near by Atlantic coast of USA The greater snow goose population increased from about 50,000 birds in 1966 to over 700,000 birds in 2004 .

A concise summary of the information obtained, regarding the weight, height and habitation of birds most frequently involved in collisions with aircraft, during this research project is presented in Table 1. 
Table 1: Physical Characteristics and Habitats of the Birds Significant for the Aviation

\begin{tabular}{|c|c|c|c|c|c|c|}
\hline \multirow{2}{*}{ Family } & \multirow{2}{*}{ Type of bird } & \multicolumn{2}{|c|}{ Weight [kg] } & \multicolumn{2}{|c|}{ Length [m] } & \multirow{2}{*}{ Where found } \\
\hline & & $\min$ & $\max$ & $\min$ & $\max$ & \\
\hline \multirow{3}{*}{ Penguins } & Emperor & 22.70 & 45.40 & 1.10 & 1.30 & Antarctica \\
\hline & \begin{tabular}{|l|} 
Southern \\
Rock hopper
\end{tabular} & 2.00 & 3.40 & 0.48 & 0.58 & Pacific and Indian Oceans, South America \\
\hline & Magellanic & 2.70 & 6.50 & 0.61 & 0.76 & Chile, Argentina, Falkland Islands \\
\hline \multirow{2}{*}{ Robin } & American Robin & 0.06 & 0.09 & 0.23 & 0.28 & $\begin{array}{l}\text { Southern Canada, USA (Towns, parks, } \\
\text { gardens) }\end{array}$ \\
\hline & $\begin{array}{l}\text { European } \\
\text { Robin }\end{array}$ & 0.02 & 0.02 & 1.25 & 1.40 & All over Europe (Towns, parks, gardens) \\
\hline \multirow{3}{*}{ Eagle } & Harpy Eagle & 4.00 & 9.00 & 0.97 & 1.00 & $\begin{array}{l}\text { Near rainforests in Central and South } \\
\text { America }\end{array}$ \\
\hline & Golden Eagle & 2.50 & 3.25 & 0.66 & 1.02 & Asia, USA, Scotland, Spain etc \\
\hline & $\begin{array}{l}\text { African Crowned } \\
\text { Eagle }\end{array}$ & 2.55 & 4.70 & 0.80 & 0.99 & Southern Africa-(forests) \\
\hline \multirow{3}{*}{ Hawk } & $\begin{array}{l}\text { Red shouldered } \\
\text { Hawk }\end{array}$ & 0.55 & 0.70 & 0.43 & 0.58 & USA \\
\hline & Ferruginous Hawk & 0.95 & 2.30 & 0.51 & 0.69 & North America \\
\hline & Sparrow Hawk & 0.19 & 0.34 & 0.29 & 0.41 & Europe, Ireland, Canary Islands \\
\hline \multirow{3}{*}{ Gulls } & Black-headed Gull & 0.25 & 0.33 & 0.38 & 0.44 & North America, Canada, Europe \\
\hline & Common Gull & 0.29 & 0.48 & 0.40 & 0.46 & Asia, Northern Europe, American \\
\hline & Iceland Gull & 0.82 & 1.10 & 0.50 & 0.64 & Iceland, Arctic \\
\hline \multirow{3}{*}{ Geese } & Canadian & 2.50 & 6.50 & 0.75 & 1.10 & North America, Northern Europe \\
\hline & Chinese & 4.00 & 10.00 & 0.50 & 0.76 & Asia \\
\hline & Bar Headed & 1.87 & 3.20 & 71.00 & 76.00 & Central Asia \\
\hline \multirow{2}{*}{ Raven } & White-necked & 0.76 & 0.87 & 0.50 & 0.54 & Eastern and Southern Africa \\
\hline & Northern & 0.69 & 2.00 & 0.56 & 0.78 & Northern hemisphere \\
\hline \multirow{3}{*}{ Vulture } & Black vulture & 1.60 & 2.75 & 0.56 & 0.74 & Canda, USA, Mexico, South America \\
\hline & Red headed & 3.50 & 6.30 & 0.76 & 0.86 & Southeast Asia, Indian Subcontinent \\
\hline & Ruppell's & 6.40 & 9.00 & 0.85 & 1.03 & Central Africa \\
\hline \multirow{3}{*}{ Sparrow } & Chestnut & 0.01 & 0.02 & 0.11 & 0.12 & East of Africa, Darfur, Tanzania \\
\hline & House & 0.02 & 0.04 & 0.14 & 0.18 & Europe, Asia, Australia, Africa, America \\
\hline & Eurasian tree & 0.02 & & 0.13 & 0.14 & Eurasia, Southeast Asia \\
\hline \multirow{3}{*}{ Swans } & Coscoroba & 3.20 & 5.40 & 0.88 & 1.15 & South America \\
\hline & Black swan & 3.70 & 9.00 & 1.10 & 1.42 & Australia, New Zealand \\
\hline & Whooper swan & 8.20 & 11.40 & 1.40 & 1.65 & Iceland, Subarctic Europe, Asia \\
\hline \multirow[b]{2}{*}{ Crows } & American & 0.32 & 0.62 & 0.40 & 0.53 & North America, Arctic \\
\hline & Hooded & 0.51 & & 0.48 & 0.52 & $\begin{array}{l}\text { Northern, Eastern and South-Eastern Eu- } \\
\text { rope, Middle East }\end{array}$ \\
\hline \multirow[t]{2}{*}{ Ducks } & Mallard & 0.72 & 1.58 & 0.50 & 0.65 & $\begin{array}{l}\text { Europe, Asia, North Africa, America, New } \\
\text { Zealand, Australia }\end{array}$ \\
\hline & Mandarin & 0.63 & 1.08 & 0.41 & 0.49 & East Asia, Europe \\
\hline \multirow[t]{2}{*}{ Falcon } & Gyrfalcon & 0.81 & 2.10 & 0.48 & 0.65 & $\begin{array}{l}\text { Arctic, islands of North America, Europe } \\
\text { and Asia }\end{array}$ \\
\hline & Peregrine & 0.42 & 1.50 & 0.34 & 0.58 & Canada, Europe, parts of Asia \\
\hline
\end{tabular}


The information presented in Table 1 is of significant importance to the aircraft designers that continuously face decisions regarding the shapes and forms of the future aircraft in the respect to the strengths of materials used for fuselage and wings. This is one of the main drivers of the design, as the negative functionability events will take place at any instant of time when the acting loads on the aircraft exceed the strength of materials used, thus:

$\{\mathrm{NFE}\}=\{$ Acting Load $>$ Strength of Material $\}=(\mathrm{L}>\mathrm{S})$ Impact of the collision between high velocity flaying aircrafts and birds of a mass of several kilograms generates significant stresses on aircraft structure, which could be quantified by applying approximation method presented above (Equation 2.) Hence, the results of this research are the basis on which the active loads, generated by bird strike, could be calculated and the impulse forces quantified.

Also the information gathered in this research is beneficial to the planners and designers of the future airports and their wild life managers, as the evolutionary habits and migration paths of birds cannot be instantly changed with opening of a new airport;, however it may be important to the local businesses and population.

\section{Further Research}

One approach to resolve the aircraft bird strike problem is to design aircraft components that would withstand loads imposed by striking birds, allowing safe operation until landing. The most vulnerable components, transparencies and jet engines, are designed and evaluated using computer models and full scale tests. These testing techniques utilize bird measurement data. Currently, due to a lack of available data, scientists and test engineers assume that the bird density is constant.

However, in zoology it is readily available information that the percent of body mass represented by feathers differed among species, but not by sex or sex $x$ species.. For example herring gulls, vultures and laughing gulls had around 10 $\%$ of their body mass in feathers while starlings, sparrows and rock dove have around $3 \%$ of their body mass in feathers.

Bird density appears to reflect their life history. For example gulls and waterfowl both associated with long, continuous flights and floating on water, are the examples of low density spe- cies, while turkeys and vultures were a low density species that exhibit good soaring efficiency. European Starlings, House Sparrows, Common Grackles, and Brown-headed Cowbirds, among the densest species, do not depend upon these qualities for survival.

As domestic chickens are primarily terrestrial birds and have been bred to increase the muscle mass they carry, they are much denser than the wild bird species Consequently, to use the domestic chicken for an aircraft bird strike test species may be appropriate as it represents a worst case due to its high density.

Consequently, to increase the accuracy of the predictions of the impulse forces impacting the structure of an aircraft resulting from the collisions with birds it is necessary to know bird densities. To know bird density it is necessary to determine mass, wingspan, and circumference measurements of birds. Determining these measures for the family and type of birds listed in Table 1 is the next project to be completed at the MIRCE Akademy.

\section{CONCLUSION}

Since birds and aircrafts share the same space it is inevitable that collisions between them will take place. Evidently, these collisions have negative impact on both parties. Hence, it is necessary establish a scientifically based relationship between both parties in respect to each other and with the natural environment they share.

Using principles of Mirce Mechanics, in this paper a bird strike is considered as a mechanism that generate sufficient mechanical energy to cause the occurrence of a negative functionability event resulting in the motion of a system from positive to negative functionability state.

The results of the research conducted at the MIRCE Akademy to determine the physical characteristics of a selective group of birds, namely those that have the most frequent and consequential impact on the aircraft safety, is presented in this paper. The objectives of the research were to collect the data regarding the physical properties of birds, like their weight and length, which is necessary information for the calculation of the impulse force to be made for various combinations of aircrafts and birds.

Ability to predict a magnitude of the future acting loads, generated by the impact of birds on aircrafts is crucial for many design decisions that 
have to be made at conceptual stages of the creation of the future aircrafts, regarding their safety and reliability, starting from material selections engine location, fuselage shape and many others. Naturally, all of these decisions are sensitive to the geographical locations expected to be used for the aircraft under consideration as well as the potencial limitations that might be applied for a restricted flights during the migration seasons over certain corridors.

\section{ACKNOWLEDGMENT}

All the information contained in the Table 1 has been collected and produced at the MIRCE Akademy, under author's supervision, by Miss Amy Wyatt a student of the Exmouth Community College, as a part of the collaboration between these two Educational Institutions in Devon, UK.

\section{REFERENCES}

1) Accident Report, NTSB/AAR-10/03, PB2010910403, Loss of Thrust in Both Engines After Encountering a Flock of Birds and Subsequent Ditching on the Hudson River US Airways Flight 1549 Airbus A320-214, N106US Weehawken, New Jersey January 15, 2009. pp. 189, May 2010.

2) Cleary, E. C., Dolbeer, R.A., and Wright, S.E., Wildlife strikes to civil aircraft in the United States, 1990-2006. U.S. Department of Transportation, Federal Aviation

3) Devaux, J. P., Substitute Bird objectives and constraints, pp 413-424, 21st Proceedings of Bird Strike Committee Europe, Israel Nature Reserves Authority, Jerusalem, Israel. 1992.

4) Dolbeer, R. A., Birds and aircraft: fighting for airspace in crowded skies, pp 37-43, Proceedings of 19th Vertebrate Pest Conference, University of California, Davis, California, USA, 2000.

5) Knezevic, J., Time to Chose Between Scientific and |Administrative Approach to Reliability, Journal of Applied Engineering Science, pp 167-173, No. 3, Year 2012, Vol 10, Belgrade, Serbia.

6) MacKinnon, B., R. Sowden, and S. Dudley, Sharing the skies: an aviation guide to the management of wildlife hazards. Transport Canada, Aviation Publishing Division, AARA, Ottawa, Ontario, Canada, pp 316 pages, 2001.

7) Richardson, W. J., and T. West, Serious bird strike accidents to military aircraft: updated list and summary, pp. 67-98, Proceedings of 25th International Bird Strike Committee Meeting, Amsterdam, Netherlands, 2000.

8) The Papers of Wilbur and Orville Wright, Marvin W. McFarland (Ed) - Volume one 18991905 Volume two 1906-1948. McGraw-Hill - Originally published: 1953, by the McGrawHill Companies, Inc.

9) Thorpe, J. 2005. Fatalities and destroyed aircraft due to bird strikes, 2002-2004 (with an appendix of animal strikes). Pages 17-24 in Proceedings of the 27th International Bird Strike Committee Meeting (Volume 1). Athens, Greece.

10) Zaczyk, I., Impact of Cosmic Radiation on Aviation Reliability and Safety, Journal of Applied Engineering Science, pp 217-223, No. 4, Year 2013, Vol 11, Belgrade, Serbia.

Paper sent to revision: 28.07.2014.

Paper ready for publication: 12.09.2014. 